\title{
Determinant factors of male involvement in birth preparedness and complication readiness at Mekelle town; a community based study
}

\author{
Haftom Gebrehiwot Weldearegay \\ Department of Midwifery, College of Health Sciences, Mekelle University, Mekelle, Ethiopia
}

Email address:

Haftom1224@yahoo.com

To cite this article:

Haftom Gebrehiwot Weldearegay. Determinant Factors of Male Involvement in Birth Preparedness and Complication Readiness at Mekelle Town; a community Based Study. Science Journal of Public Health. Vol. 3, No. 2, 2015, pp. 175-180. doi: 10.11648/j.sjph.20150302.14

\begin{abstract}
Introduction: Every pregnant woman faces risk of life-threatening obstetric complications. A birth-preparedness package promotes active preparation and assists in decision-making for healthcare seeking in case of such complications. The main objective of this study was to assess the determinant factors of male involvement on birth preparedness and complication readiness at Mekelle town. Methods: A community based cross-sectional study was conducted from July to October/2014 among 376 husbands/male whose wives was delivered within the last 12 months at Mekelle town northern part of Ethiopia. Multi stage stratified sampling technique with Probabilities proportional to size was used. Study subjects again were selected by systematic random sampling technique from 6 randomly selected kebelle's in the town. Data was collected using structured interview questionnaire and entered, cleaned and analyzed using SPPS version 20.00. Bivariate and multivariate logistic regression analysis was used to avoid any confounding variables. Results: A total of 376 husbands were participated in the study with $95 \%$ response rate. About $60 \%$ of the husbands had participated in birth preparedness and complication readiness (BP/CR). The study revealed that husbands were more likely to participate in birth preparedness if they had better knowledge in postnatal danger signs $(\mathrm{AOR}=4.29,95 \% \mathrm{CI}$ : 1.54-11.94) and with good ( $\mathrm{AOR}=9.05,95 \% \mathrm{CI}=4.27-19.18)$ \& better knowledge on birth preparedness ( $\mathrm{AOR}=16.50,95 \% \mathrm{CI}=7.25-37.58)$. Conclusion \& Recommendation: Male involvement in birth preparedness and complication readiness is still low in this study. But there is slightly better knowledge on postnatal danger signs and knowledge on birth preparedness and complication readiness. Thus, male awareness in postnatal danger signs and birth preparedness should be increased by local and other concerned bodies to make husbands to share in birth preparedness.
\end{abstract}

Keywords: Male, Birth Preparedness, Mekelle, Complication

\section{Introduction}

In sub-Saharan Africa, pregnancy and childbirth continue to be viewed as solely a woman's issue. A male companion at antenatal care is rare and in many communities, it is unthinkable to find male companions accompanying a woman to the labour room during delivery. Thus male involvement in reproductive health has been promoted as a promising new strategy for improving maternal and child health [1,2]. Birth preparedness is a relatively common strategy employed in implementing safe motherhood programs which may be affected by male partner participation because husbands were the most influential decision-maker and as the key member of the family [3].

The 2010 World Health Organization report indicated that, more than half a million women were dying each year from the complications of pregnancy and childbirth, in which $99 \%$ of these deaths occurring in the developing world. Besides this, for every 100,000 live births, 240 women died during pregnancy, childbirth, or the postpartum period in which are mostly from developed countries [4,5]. Decreasing a maternal by three fourth is one of the Millennium Development Goal five (MDG-5) which is should be achieved 2015 [6].

In Ethiopia, the maternal mortality ratio is estimated to be 676 deaths per 100,000 live births, which is among the highest in the world [7]. According to the Ethiopian Federal Ministry of Health, health and health related indicators $82.20 \%$ coverage for ANC, only $18.4 \%$ of the deliveries are attended by health professionals, $42.10 \%$ for postnatal care coverage [8]. 
Most of the causes of maternal morbidity and mortality are preventable and attributed to the three delays; delay in recognizing problem and delay to seek care, delay to reach place of care, and delay to receive appropriate care. Birth preparedness is educating the mother and her family to recognize the normal signs of labour $[2,3]$.

In many societies in the world, cultural beliefs and lack of awareness inhibit preparation in advance for delivery and expected baby. Since no action is taken prior to the delivery, the family tries to act only when labor begins. The majority of pregnant women and their families do not know how to recognize the danger signs of complications. When complications occur, the unprepared family will waste a great deal of time in recognizing the problem, getting organized, getting money, finding transport and reaching the appropriate referral facility [7].

It is difficult to predict which pregnancy, delivery or post delivery period will experience complications; hence birth preparedness and complication readiness plan is recommended with the notion of pregnancy is risk [6]. Birth Preparedness and Complication Readiness strategy encourage women to be informed of danger signs of obstetric complications and emergencies,

Choose a preferred birth place and attendant at birth, make advance arrangement with the attendant at birth, arrange for transport to skilled care site in case of emergence, saving or arranging alternative funds for costs of skilled and emergency care, and finding a companion to

Be with the woman at birth or to accompany her to emergency care source. Other measures include identifying a compatible blood donor in case of hemorrhage, obtaining permission from the head of household to seek skilled care in the event that a birth emergency occurs in his absence and arrange a source of household support to provide temporary family care during her absence [8,9].

Studies conducted on pregnant mother in Ethiopia showed that one of the factors of affecting antenatal care ( $15.5 \%$ husband's disapproval for antenatal attendance, and only $21 \%$ of pregnant mother were accompanied by their husbands to the antenatal clinic) [10].

Therefore, male involvement in maternal health is key to ensuring considerable reduction in maternal mortality. This study was conducted to ascertain male involvement in Birth preparedness and complication readiness strategy as important support structures to help reduce delays in accessing maternal health care especially during emergencies.

\section{Methods and Materials}

\subsection{Study Area and Period}

This study was conducted from July to October/2014 in Mekelle City. Mekelle is capital city of Tigray Regional State and is located in the Northern part of Ethiopia, at $783 \mathrm{~km}$ from the capital city, Addis Ababa. Mekelle has weyna-dega climatic conditions, which is administratively divided into seven sub cities.
The area of study was selected by its lack of tangible previous research under this topic and its convenience access to the investigators.

\subsection{Study Design and Source Population}

A community based cross-sectional study was conducted among households targeting husbands with having at least one child of less than one year of age in Mekelle town.

All husbands whose wife had a child less than one years of age were included in the study while husbands who were not stay together with their wives during pregnancy and birth of the child and those who were critically ill were excluded from the study.

\subsection{Sample Size Determination and Sample Procedure}

The sample of 398 husbands was determined using single population proportion formula with $95 \%$ level of confidence, $5 \%$ margin of error and $21 \%$ of husbands estimated to be participated in birth preparedness [11]. Considering, 1.5 design effects and $10 \%$ non-response rate. From total 7 sub city in the town 3 of them were selected by lottery method. For each selected kebeles the sample size was allocated proportionally according to their population. Then sampling frame was formed by conducting a census to register all households of husband with wife having less than one year age child. Finally husbands were selected by systematic random sampling technique.

\subsection{Data Collection and Procedures}

Data was collected using structured questionnaire. The questionnaire was designed in English and was translated to Tigrigna version for better understanding by data collectors and interviewees during the interview time. Finally the instrument was administered in Tigrigna. A total of four data collectors of nurses with degree holder and one supervisor with qualification of Master of public health were involved in data collection.

\subsection{Data Processing and Analysis}

Data were coded, entered and cleaned. Data analysis was carried out using SPSS version 20 software package.

Simple descriptive statistics such as frequencies, means, and standard deviations were done as appropriate and The associated factor between the different variables in relation to the outcome variable was measured by odds ratio with $95 \%$ confidence interval.

\subsection{Data Quality Assurance and Control Method}

One day training for data collectors was conducted at Mekelle University and Pre-test was done to $5 \%$ of the husbands outside the selected rural community to check the effectiveness of the questioners. Revision was made on the questionnaire as necessary depending on the first of the pretest. Time interval needed per questionnaire was determined after pre-testing. 
Following data collection procedures, checking for the completeness of the questionnaire by principal investigator, proper categorization and coding of data were done to assure data quality.

\subsection{Ethical Consideration}

Ethical clearance was obtained from the ethical review committee of Mekelle University College of Health Sciences. All concerned bodies were officially contacted through letters and permission was obtained at all levels. After the purposes and the procedure of the study were explained, verbal informed consent was obtained from all respondents. Each study participants was informed about confidentiality or privacy throughout the whole process.

\section{Results}

\subsection{Characteristics of Study Participants}

Table 1. Socio-Demographic characteristics of respondents at Mekelle, Tigray region, Ethiopia, $(N=376)$.

\begin{tabular}{|c|c|c|}
\hline Variables & Frequency & $\%$ \\
\hline \multicolumn{3}{|l|}{ Age in years } \\
\hline $18-29$ & 60 & 16.00 \\
\hline $30-39$ & 174 & 46.30 \\
\hline $40-49$ & 112 & 29.80 \\
\hline$\geq 50$ & 30 & 8.00 \\
\hline \multicolumn{3}{|l|}{ Ethnicity } \\
\hline Tigray & 373 & 99.20 \\
\hline Amhara & 3 & 0.80 \\
\hline \multicolumn{3}{|l|}{ Religion } \\
\hline Orthodox & 375 & 99.70 \\
\hline Muslim & 1 & 0.20 \\
\hline \multicolumn{3}{|c|}{ Husband's education } \\
\hline Illiterate & 174 & 46.30 \\
\hline Read and write & 123 & 32.70 \\
\hline Formal education & 79 & 21.00 \\
\hline \multicolumn{3}{|c|}{ Husband's occupation } \\
\hline Farmer & 320 & 85.10 \\
\hline Employed & 32 & 8.50 \\
\hline Self business & 24 & 6.40 \\
\hline \multicolumn{3}{|l|}{ Wife's age } \\
\hline$<20$ & 52 & 13.80 \\
\hline $20-34$ & 223 & 59.30 \\
\hline $35-49$ & 101 & 26.90 \\
\hline \multicolumn{3}{|l|}{ Wife's education } \\
\hline Illiterate & 228 & 60.60 \\
\hline Read and write & 42 & 11.20 \\
\hline Formal education & 106 & 28.20 \\
\hline \multicolumn{3}{|l|}{ Wife's occupation } \\
\hline Farmer & 315 & 83.80 \\
\hline Employed & 15 & 4.00 \\
\hline Self business & 46 & 12.20 \\
\hline \multicolumn{3}{|c|}{ Monthly income in Ethiopian birr } \\
\hline$<500$ & 179 & 47.60 \\
\hline $500-1000$ & 133 & 35.40 \\
\hline$>1000$ & 64 & 17.00 \\
\hline
\end{tabular}

The mean age of study participant was $37.46 \pm 8.27$. Almost all $373(99.20 \%)$ were Tigray in ethnicity and 375(99.70) were orthodox in religion. In addition, near half of the respondents, $174(46.30 \%)$ and majority of them were farmers $(85.1 \%)$ by employment.
Regarding their wives' socio-demographic characteristics, their mean age was 28.9 (SD \pm 6.9 years) and majority $52(13.80 \%)$, them were less than 20 years old. About 228 $(60.60 \%)$ were illiterate, and majority of them were farmers $315(83.80 \%)$ in occupation. About half of the households, 179(47.60\%), had income less than 500.00 Ethiopian birr monthly (Table1).

\subsection{Husband's Knowledge in Birth Preparedness and Complication Readiness}

This study assessed the knowledge of husbands in BP/CR. Majority of respondents, $88.00 \%$ replied as they knew husband birth preparedness. Among those 301(80.10\%) were heard about the mother and new born clean clothes preparation, $287(76.30 \%$ ) were to saving money for child birth, $234(62.20 \%)$ to identification of place of birth, $123(32.70 \%)$ were to identification of skilled birth attendance and few $65(17.30 \%)$ had the information about identifying blood donor for complications in birth (Table 2).

Table 2. Knowledge of husbands on BP/CR at Mekelle Tigray region, Ethiopia, $(N=376)$.

\begin{tabular}{lll}
\hline Variable & Yes (\%) & No (\%) \\
\hline $\begin{array}{l}\text { Arranging for postpartum cultural food } \\
\text { expenses }\end{array}$ & $280(74.50)$ & $96(25.50)$ \\
$\begin{array}{l}\text { Saving money for Mother's health care } \\
\text { Identifying a mode of transportation }\end{array}$ & $287(76.30)$ & $89(23.70)$ \\
$\begin{array}{l}\text { Identifying place of delivery } \\
\text { Clean clothes \& other materials for }\end{array}$ & $246(65.40)$ & $130(34.60)$ \\
Baby/Mother's & $301(80.10)$ & $75(19.90)$ \\
Savings for emergencies & $215(57.20)$ & $161(42.80)$ \\
Awareness an emergency \& it immediately & $193(51.30)$ & $183(48.70)$ \\
action & $123(32.70)$ & $253(67.30)$ \\
Arrangement for skilled birth assistance & $166(44.10)$ & $210(55.90)$ \\
Identifying decision maker for emergency & $65(17.30)$ & $311(82.70)$ \\
$\begin{array}{l}\text { Arranging blood donors } \\
\text { Identifying date of birth }\end{array}$ & $219(58.20)$ & $157(41.80)$ \\
Prevention of HIV mother to child & $222(59.00)$ & $154(41.00)$ \\
\hline
\end{tabular}

\subsection{Level of Husband Participation in Birth Preparedness}

In this study husbands practiced at least five components were considered as participated in birth preparedness. Accordingly, majority of the husbands, 227(60.4\%) were participated in birth preparedness and the rest, 124(32.98) of them had poor birth preparedness practice (Table 3).

Table 3. The Level of husbands' participation in BP/CR at Mekelle, Tigray Region, Ethiopia, $(N=376)$.

\begin{tabular}{lll}
\hline Variables & Frequency & $\%$ \\
\hline Birth preparedness practice & & \\
Poor practice & 149 & 39.60 \\
Good practice & 123 & 32.70 \\
Better practice & 104 & 27.70 \\
Participated in BP/CR(Over all practices) & $227^{*}$ & $60.40^{*}$ \\
\hline
\end{tabular}

*overall husbands' practice

\subsection{Factors Associated with Husband's Participation in Birth Preparedness and Complication Readiness}

Table four, showed bivariate and multiple logistic 
regression analysis of socio-demographic variables with $\mathrm{BP} / \mathrm{CR}$. Bivariate analysis showed that, illiterate $(\mathrm{OR}=1.90$ (95\% $\mathrm{CI}=1.18-3.06)$, those able to read and write $(\mathrm{OR}=$ 3.47(95\% CI=1.9-6.34)), employed husbands (OR=0.26 95\% $\mathrm{CI}=0.09-0.79$ ), average monthly income more than 1000 birr, $(\mathrm{OR}=2.8995 \% \mathrm{CI}=1.49-5.94)$ were significantly associated with husbands' practice on birth preparedness.

In addition to above husbands' wives able to read and write $(\mathrm{OR}=2.12 \quad 95 \% \quad \mathrm{CI}=1.05-4.28)$ and with formal education $(\mathrm{OR}=3.07$ 95\% $\mathrm{CI}=1.83-5.16)$, whose wives involved in self business job $(\mathrm{OR}=2.74(95 \% \mathrm{CI}=1.31-5.71)$ were associated with birth preparedness.

In biavriate analysis it is also found that, husbands' whose wife's gave birth once at health facility $(\mathrm{OR}=2.1595 \%$ $\mathrm{CI}=1.02-4.55)$, husbands planed to the conception of the index child was $(1.75(95 \% \mathrm{CI}=1.15-2.66)$, husbands who felt nearby health facility $(\mathrm{OR}=2.73 \quad(95 \% \mathrm{CI}=1.73-4.35)$ were more likely to participate in birth preparedness.

Regarding husbands knowledge on danger signs of pregnancy and labour, the husbands who had better knowledge in pregnancy $(\mathrm{OR}=7.72(95 \% \mathrm{CI}=4.32-13.97)$ and danger signs during labour $(\mathrm{OR}=9.81(95 \% \mathrm{CI}=4.1-19.28)$ were more likely to participate. In addition to this, husbands with good $(\mathrm{OR}=3.32(95 \% \quad \mathrm{CI}=1.68-6.54)$ and better $(\mathrm{OR}=16.72(95 \% \mathrm{CI}=8.67-32.25)$ knowledge in postnatal danger signs were also more likely to participate in birth preparedness. Those husbands had good and better knowledge in birth preparedness were also more likely to participate in birth preparedness than those with poor knowledge $(\mathrm{OR}=13.86(95 \% \mathrm{CI}=7.01-27.40)$ and $(\mathrm{OR}=42.9$ (95\% $\mathrm{CI}=20.61-89.32)$ respectively.

Using multiple logistic regression, husbands' better knowledge in the postnatal danger signs $(\mathrm{AOR}=4.2995 \%$ $\mathrm{CI}=1.54-11.93)$, good knowledge in birth preparedness knowledge $(\mathrm{AOR}=9.05$ and, $95 \% \mathrm{CI}=4.27-19.18)$ those who had better knowledge $(\mathrm{AOR}=16.50$ and $95 \% \mathrm{CI}=7.25-37.6)$ were significantly associated with participation in birth preparedness (Table 4).

Table 4. Multiple logistic regression analysis for factors associated with BP/CR at Mekelle, Tigray region, Ethiopia.

\begin{tabular}{|c|c|c|c|c|}
\hline \multirow{2}{*}{ Variables } & \multicolumn{2}{|c|}{ Participated in BP/CR } & \multicolumn{2}{|c|}{ Odds ratio $(95 \% \mathrm{CI})$} \\
\hline & Yes $(\%)$ & No $(\%)$ & COR & AOR \\
\hline \multicolumn{5}{|l|}{ Husband's education } \\
\hline Illiterate & $86(22.9)$ & $88(23.4)$ & 1.00 & 1.00 \\
\hline Read and write & $80(21.3)$ & $43(11.4)$ & $1.9(1.18-3.06)^{*}$ & $0.81(0.41-1.62)$ \\
\hline Literate in formal educations & $61(16.2)$ & $18(4.8)$ & $3.47(1.9-6.34)^{*}$ & $1.02(0.4-2.60)$ \\
\hline \multicolumn{5}{|l|}{ Wife's education } \\
\hline Illiterate & $117(31.1)$ & $111(29.5)$ & 1.00 & 1.00 \\
\hline Read and write & $29(7.7)$ & $13(3.5)$ & $2.12(1.05-4.3)^{*}$ & $1.9(0.7-5.19)$ \\
\hline Literate informal educations & $81(21.5)$ & $25(6.6)$ & $3.07(1.83-5.2)^{*}$ & $1.75(0.77-3.97)$ \\
\hline \multicolumn{5}{|l|}{ Husband's occupation } \\
\hline Farmer & $182(48.4)$ & $138(30.9)$ & 1.00 & 1.00 \\
\hline Employed & $25(6.6)$ & $7(1.9)$ & $0.26(0.09-0.79)$ & $0.88(0.2-3.57)$ \\
\hline Self business \& daily works & $20(5.3)$ & $4(1.1)$ & $0.71(0.18-2.79)$ & $1.8(0.37-8.83)$ \\
\hline \multicolumn{5}{|l|}{ Wife's occupation } \\
\hline Farmer & $179(47.6)$ & $136(36.2)$ & 1.00 & 1.00 \\
\hline Employed & $12(3.2)$ & $3(0.8)$ & $3.04(0.84-10.98) *$ & $0.47(0.09-2.58$ \\
\hline Self business \& daily works & $36(9.6)$ & $10(2.7)$ & $2.74(1.31-5.71)^{*}$ & $0.54(0.15-2.0)$ \\
\hline \multicolumn{5}{|l|}{ Husband's plan to conception } \\
\hline Yes & $145(38.6)$ & $75(19.9)$ & $1.75(1.15-2.66)^{*}$ & $1.16(0.62-2.19)$ \\
\hline No & $82(21.8)$ & $74(19.7)$ & 1.00 & 1.00 \\
\hline \multicolumn{5}{|l|}{ Husband felt near facility } \\
\hline Yes & $180(47.9)$ & $87(23.1)$ & $2.73(1.73-4.35)^{*}$ & $1.41(0.72-2.56)$ \\
\hline No & $47(12.5)$ & $62(16.5)$ & 1.00 & 1.00 \\
\hline \multicolumn{5}{|c|}{ Knowledge on Pregnancy danger signs } \\
\hline Poor knowledge & $23(6.1)$ & $52(13.8)$ & 1.00 & 1.00 \\
\hline Good knowledge & $39(10.4)$ & $49(13)$ & $1.79(0.94-3.43)$ & $1.32(0.53-3.26)$ \\
\hline Better knowledge & $165(43.9)$ & $48(12.8)$ & $7.72(4.32-13.97)^{*}$ & $1.82(0.73-4.56)$ \\
\hline \multicolumn{5}{|c|}{ Knowledge postnatal danger signs } \\
\hline Poor knowledge & $16(4.3)$ & $60(16)$ & & \\
\hline Good knowledge & $46(12.2)$ & $52(13.8)$ & $3.32(1.68-6.54)^{*}$ & $2.34(0.92-5.98$ \\
\hline Better knowledge & $165(43.9)$ & $37(9.8)$ & $16.72(8.67-32.3 *$ & $4.29(1.54-11.93 *$ \\
\hline \multicolumn{5}{|c|}{ Knowledge on Birth preparedness } \\
\hline Poor knowledge & $14(3.7)$ & $91(24.2)$ & 1.00 & 1.00 \\
\hline Good knowledge & $81(21.5)$ & $38(10.1)$ & $13.9(7.01-27.4)^{*}$ & $9.05(4.27-19.2)^{*}$ \\
\hline Better knowledge & $132(35.1)$ & $20(5.3)$ & $42.9(20.6-89.32)^{*}$ & $16.5(7.25-37.6)^{*}$ \\
\hline
\end{tabular}

* Statistically significant at $\mathrm{p}<0.05$

\section{Discussion}

This community-based study assessed husband participation in birth preparedness and factors associated with participation in $\mathrm{BP} / \mathrm{CR}$ among husbands during pregnancy at Mekelle town.

This study showed that majority of $(72.1 \%)$ husbands was aware about birth preparedness for at least five of its 
components. But only $60.4 \%$ of them were participated in birth preparedness during the conception and pregnancy of their child. This finding is similar with the study conducted in 2006, Nepal in which 55\% husbands participated in birth preparedness [13].

Coming to the specific practices of husbands' in birth preparedness, in this study about $73 \%$ of them have prepared clean clothes for mother and baby before delivery. Besides this about $47 \%$ husbands identified place of delivery for their wife. This finding is higher when it is compared with the study done during 2006 Nepal and 2010 Northern Nigeria in which $8.9 \%$ of Nepalese [13] and $22.7 \%$ of Northern Nigerian husbands prepared clean clothes for the mother and baby. The finding for indentifying place of delivery is also higher compared with the study in Northern Nigeria 9\%[12]. Regarding saving money for maternal health care in our study $66 \%$ of husbands saved money for emergency and it is similar with the finding of study done in Nepal 48.5\% [13].

This study also tried to identify certain factor which can be associated with husband participation in birth preparedness. This study has revealed husbands' awareness of postnatal danger signs and husbands knowledge in birth preparedness as influencing factors for husband participation in birth preparedness. Husbands with better knowledge in the postnatal danger signs were 4 times more likely to participate in birth preparedness than those with poor knowledge. The possible reason could be severity of the complication usually unexpected in any type of birth.

The husbands with good knowledge in birth preparedness were more likely participated in birth preparedness compared to those had poor knowledge. The same as to the good knowledge, those who had better knowledge were also more likely to participate than those with poor knowledge of birth preparedness ( $\mathrm{AOR}=16.50$ and $95 \% \mathrm{CI}=7.25-37.6)$. Since being aware is the basic element for behavioral changes, could be the reason. This is similar with study done in Kenya in which low knowledge on complication is associated with partners[8,12,13].

In Ethiopia, women traditionally enjoy little independent decision making on most individual and family issues, including the option to choose whether to give birth in a health facility or seek the assistance of a trained provider. Though women in the country have constitutional rights of participation in decision making, their involvement is limited at all levels $[13,14]$

\section{Conclusion and Recommendations}

Husbands are aware of the $\mathrm{BP} / \mathrm{CR}$, prepared in practice and participated in birth.

Husband with better knowledge in postnatal danger signs and at least having good knowledge in $\mathrm{BP} / \mathrm{CR}$ are the independent predictors of birth preparedness.

Therefore the policy makers should work to promote the awareness of male partners on the danger signs during postnatal period and birth preparedness, and inform the community about the importance of husbands' participation for child and mothers. The health office should also strengthen the health education about danger signs of pregnancy and postnatal period to increase the husbands' participation.

In addition to this, counseling should be given for mothers by health care providers during antenatal, delivery and immunization period to convince their husbands about the health risks and the actual maternal health problems which in turns make husbands save money, pay in case emergency arise, identify mode of transportation to health facility, identify blood donor ahead before emergency happen.

Apart from these, husband involvement strategy in at least one antenatal visit should be promoted for the readiness of complications in pregnancy, labor and after labor and to inform them by creating a link through their wives from the midwife or any attendant. Also, health education should be provided for community concerning identification of danger signs in postnatal period and the role of husband in birth preparedness and complication readiness.

Lastly we recommend conducting further studies on barriers of husbands' participation in maternal care.

\section{Abbreviations}

$\mathrm{BP} / \mathrm{CR}$ : Birth preparedness and complication readiness

ANC: Antenatal care services

MDGs: Millennium Development Goals

\section{References}

[1] United Nation Population Fund; SI and Burger, M.: Parenting a new approach to sexual and reproductive health. Technical paper No.3, 2000.

[2] Federal Democratic Republic of Ethiopian. Ministry of Health: Antenatal Care Blended learning module for the Health extension Programmme, HEAT in Africa.

[3] Johns Hopkins Program for International Education in Gynecology and Obstetrics, Monitoring birth preparation and complication readiness tool and indicators for maternal and child health: 2004

[4] Cook K, Dickens BM. Wilson A. Scarrow S. Advancing safe motherhood through human rights. Geneva: WHO; 2001.

[5] World Health Organization: Media Centre. Maternal mortality Fact sheet No. 384, accessed in mediainquires@who.int May 2012.

[6] World Health Organization: Mother-baby package; implementing safe motherhood in countries. Practical Guide. Maternal health and safe mother hood programmed. In division of Family Health Geneva: World Health Organization, 2005.

[7] JHPIEGO; Maternal and Neonatal Health Program: Monitoring Birth Preparedness and Complication Readiness; Tools and Indicators for Maternal and Newborn Health [Internet]. Hopkins: Bloomberg School of Public Health, Center for Communication Programs, Family Care International; 2004. 
[8] Hiluf M, Fantahun M: Birth Preparedness and Complication Readiness among women in Adigrat town, north Ethiopia. Ethiop J Health Dev 2007, 22(1):14-20.

[9] Federal democratic republic of Ethiopia ministry of health, basic emergency obstetric \& newborn care (BEMONC) training manual. A: Ministry of health, April $2010,1^{\text {st }}$ Ed.

[10] Kassyou H. Factors affecting antenatal care attendance in Maichew Town, Southern Tigray 2008.

[11] Dessie Y. Husbands are not involving on their wife's antenatal care follow up. In Harari region, Ethiopia, 2012.
[12] Z Iliyasu,IS Abubak ar, HS Galadanci, MH Aliyu, Birth preparedness and complication readiness and Fathers' participation in maternity care in a Northern Nigerian community. African Journal of Reproductive Health, 2010.

[13] Analyses Survey in Husband's participation in pregnancy care: The voice of Nepalese men 2006.

[14] Gender inequality and women's empowerment. Ethiopian society of population studies Addis Ababa, 2008. 